that of others, he was induced to consider this a most favourable case for an operation, as the disease was of the kind that never returns. It was unlike the soft tumours you met in this region, which were of a malignant character. He would now saw across the tumour for their satisfaction, and his own, and he expected to find it composed of an intermixture of bone and cartilage. Having sawn across the bone, Mr. F. proceeded to say that the tumour was much denser than any one of a similar kind he had ever seen in the same situation; it was not, however, uncommon in the lower jaw, as the students might see for themselves in several preparations in his collection of cases, in which he had removed the lower jaw for the same disease. He had every hope of the ultimate success of the operation. He was certain that the whole diseased mass was removed, and if the patient recovered the shock of such a proceeding, of which, from her youth and previous good health, he had the most sanguine hopes, he had little donbt but that the girl would be rescued from a certain death.

From the day of the operation up to the present time, the case has proceeded in the most favourable manner. Suppuration commenced on the 5 th, at the sides of the mouth and nostril. On the 7 th the pulse, which had previously ranged between 120 and 130 , descended to 112 , and healthy granulations had filled up a great portion of the wound. On the 12th the child was permitted to eat some chicken for dinner, and she is now nearly convalescent.

\section{POOR-LAW MEDICAL RELIEF.}

TO THE EDITORS OF THE PROVINCIAL MEDICAL AND SURGICAL JOURNAL.

Gentlemen, - A communication from the President of the College of Surgeons, published in a recent number of your Journal, appears likely to make an erroneous impression respecting the present state and prospects of the question of poor-law medical relief. I therefore beg permission to comment briefly on that letter, and to show that Mr. Guthrie's statements afford no sufficient reason, either for abstaining from further appeals to Parliament, or for placing confidence in the poor-law commissioners.

The promised amendments which, on more than one occasion, Mr. Guthrie has rather pompously announced, as the result of his interposition, are identical with those recommended by the commissioners, in their Report of Dec. 31, 1839; and are therefore attributable, not to Mr. Guthrie's recent conferences with Mr. G. C. Lewis, but to the Report and Minutes of Evidence of the Parliamentary Committee in 1838, and also to the repeated applications of the Medical Associations to Government and Parliament, for redress and protection.

While Mr. Guthrie and others merit the thanks of the profession for their efforts on behalf of union surgeons-efforts which the latter gentlemen have neither the courage nor energy to make for themselves-it is an act of mere justice to trace to their real source, those reforms which must soon be adopted, and which we may be sure would never have been effected by the commissioners, but for their apprehension of legislative interference.

So long as the poor-law authorities had the power of withholding what was due to the medical profession and the sick poor, they refused to grant it. They deserve, therefore, no credit for their present apparent readiness to comply with the demands of reason and humanity. When Mr. Guthrie speaks (facetiously?) of the alterations which the commissioners "have been pleased to make in their regulations," he must allow us to substitute the more correct, though less polite term, forced. Can he have persuaded him self, and does he expect to convince his professiona brethren, that the poor-law commissioners are all at once benevolently disposed to mitigate the harsh and unjust system to which, for seven years, in spite of every remonstrance, they have pertinaciously adhered ? - that the unscrupulous oppressors of $\mathrm{Mr}$. Adams, of Sevenoaks, and Mr. Kington, of St. Albans (not to mention numerous other injured and insulted parochial surgeons), are the "firm friends" of the profession?-or that, to the "kindly feelings" of the authors of the large-district-and-small-salary-system, we may safely leave the future arrangement of this long contested question?

If $\mathrm{Mr}$. Guthrie would take the trouble to read the late publication of the Provincial Association, entitled "The Administration of Medical Relief to the Poor under the Poor-law Amendment Act, \&c.," he would perceive that the calumnies and gross misrepresentations repeatedly circulated by the commissioners on this subject, are totally irreconcilable with the existence of any just and liberal feelings towards the medical profession. Far be it from me to question the truth of Mr. Guthrie's assertion with regard to Mr. G. C. Lewis. It is more than probable that two of the assistant-commissioners are equally well disrosed. But we form an estimate of the commis sioners, not from the opinions of a very small minority of their number, but from the proceedings of the majority, and from the reports of the central board, which are quite sufficient to show their hostile "animus."

They have displayed much policy in this contest. When medical practitioners have been on the point of some vigorous and decisive movement, the commissioners have contrived to detach a portion of the assailing body by offers of peace and concession. They have thus succeeded, at different times, in cajoling the presidents, both of anti-reform colleges, and of radical associations.

Their main object clearly is, to prevent the intervention of Parliament. To effect this, they do not scruple to promise such alterations as may induce the medical profession to believe that legislation is unnecessary, and that the matter may be safely left to Somerset-house discretion.

If we now retire from the field, we shall find that the forthcoming amendments, if any, are imperfect and unsatisfactory. Besides, the commissioners have not even proposed to abolish some of the more serious evils of their system, such as the distance of rural parishes from the union medical officer, the enormous population of districts, and the difficulties which the poor encounter in procuring orders for medical relief.

That neither the commissioners, nor their friend the president, may succeed in checking the exertions of provincial practitioners, at the present important crisis, is, Gentlemen, the earnest hope of

\section{Your obedient servant}

Feb. 19, 1812

A Provincial Sorgeon.

\section{PRACTICAL SUMMARY OF FACTS IN MEDICINE AND SURGERY.}

\section{PREPARATION OF TANNIN.}

Pelouze's process for the preparation of tannin consists in treating nutgalls with $x$ ther, by the process of percolation. $\Lambda$ displacement apparatus of proper size being provided, the galls in fine powder are introduced, so that when slightly compressed, the apparatus shall be one-half filled; sulphuric $x$ ther of commerce is now to be added, until the apparatus is full. 'The top of the apparatus should be partially closed, so as to prevent the evaporation of the æther, while the access of air is admitted. Thus arranged, the apparatus is allowed to remain for twenty-four hours, by 